Case Report

\title{
The Cause of Unexpected Acute Abdomen and Intra-Abdominal Hemorrhage in 24-Week Pregnant Woman: Bochdalek Hernia
}

\author{
Yavuz Savas Koca, ${ }^{1}$ Ibrahim Barut, ${ }^{2}$ İhsan Yildiz, ${ }^{1}$ and Rasih Yazkan ${ }^{3}$ \\ ${ }^{1}$ Department of General Surgery, School of Medicine, Süleyman Demirel University, Isparta, Turkey \\ ${ }^{2}$ Department of General Surgery, School of Medicine, HPB Surgery Unit, Süleyman Demirel University, Isparta, Turkey \\ ${ }^{3}$ Department of Thorax Surgery, School of Medicine, Süleyman Demirel University, Isparta, Turkey
}

Correspondence should be addressed to Yavuz Savas Koca; yavuzsavaskoca@gmail.com

Received 10 May 2016; Accepted 15 November 2016

Academic Editor: Boris Kirshtein

Copyright (C) 2016 Yavuz Savas Koca et al. This is an open access article distributed under the Creative Commons Attribution License, which permits unrestricted use, distribution, and reproduction in any medium, provided the original work is properly cited.

Bochdalek hernia $(\mathrm{BH})$ is the most common type of congenital diaphragm hernia and is rarely seen in adults. In adult patients, $\mathrm{BH}$ often remains asymptomatic or presents with nondiagnostic symptoms and may lead to complications, though rarely. The necrosis and perforations occurring in the hernia may lead to mortality. In this report, we present a 34 -year-old pregnant woman at 24 gestational weeks who presented with Bochdalek hernia causing gastric volvulus associated with perforation and intra-abdominal hemorrhage associated with splenic rupture.

\section{Introduction}

Bochdalek hernia is typically known as a neonatal disease and is rarely seen in pregnant adults. In adult patients, it often remains asymptomatic. The reported incidence of incidental $\mathrm{BH}$ is $0.17 \%$ [1] and the incidence of $\mathrm{BH}$ in pregnant adults is even rarer. Bochdalek hernia is difficult to diagnose due to nonspecific symptoms and the diagnosis of $\mathrm{BH}$ is sometimes established by the clinical manifestation of complications. The presence of complications indicates high rates of mortality and morbidity. Commonly reported complications include gastric, colonic, and esophageal necrosis and omentum hemorrhage leading to hemothorax. However, no splenic rupture caused by recessed location of the spleen has been reported in the literature. In this report, we present a 34-year-old pregnant woman with Bochdalek hernia causing total gastric necrosis, gastrointestinal perforation, and splenic rupture.

\section{Case Report}

A 34-year-old female patient at 24 gestational weeks presented to our emergency service with the complaints of vomiting, abdominal pain, weakness, and dyspnea. The patient had been suffering from vomiting for the last 10 days and from dyspnea and weakness for the last 3 days. The patient had previously presented to the hospital several times with the complaints of dyspnea and abdominal pain but had no diagnosis. The patient had a live birth delivery via caesarian section after 2 uneventful pregnancies. Physical examination revealed reduced breath sounds on the left side of the chest and diffuse abdominal tenderness and rebound tenderness on palpation. Arterial blood pressure was $70 / 50 \mathrm{mmHg}$, pulse rate was $118 / \mathrm{min}$, body temperature was $37.8^{\circ} \mathrm{C}$, and respiratory rate was $25 / \mathrm{min}$. During ultrasonographic examination of the patient, the patient had cardiopulmonary arrest. The patient was resuscitated by cardiopulmonary resuscitation in approximately 7 minutes and then was intubated and transferred to the intensive care unit.

Laboratory parameters revealed white cell count of $21,000 / \mathrm{mL}$, hemoglobin of $7.4 \mathrm{~g} / \mathrm{dL}$, platelet count of $31,8000 / \mathrm{mL}$, AST of $64 \mathrm{U} / \mathrm{L}$, ALT of $74 \mathrm{U} / \mathrm{L}$, creatinine of $1.5 \mathrm{mg} / \mathrm{dL}$, and C-reactive protein of $118 \mathrm{mg} / \mathrm{L}$. A chest X-ray was performed in the intensive care unit and showed an impression suggestive of free air under the left hemidiaphragm; therefore, a left lateral decubitus abdominal radiograph was performed and the anterior posterior image 


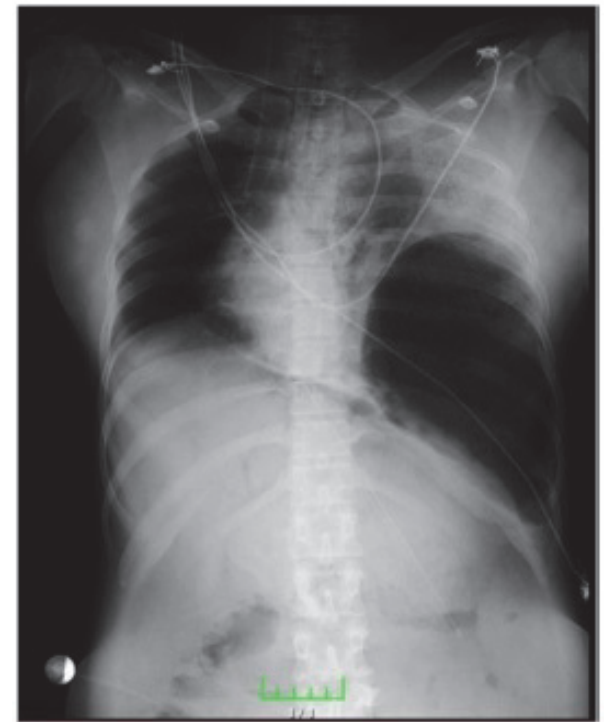

FIGURE 1: X-ray subdiaphragmatic free gas.

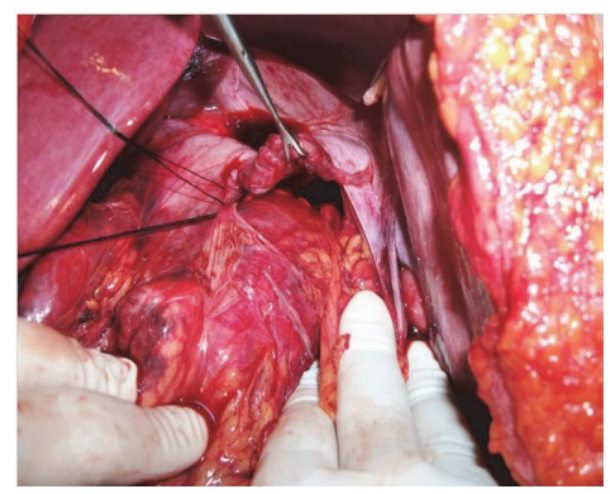

FIGURE 2: Posterior diaphragmatic defect $(14 \times 8 \mathrm{~cm})$.

showed that the free air moved to the right side (Figure 1). During the surgical decision-making process, an emergency obstetric USG examination was performed and it revealed intrauterine fetal demise.

The patient was operated on under emergency conditions. During laparotomy, there was gush of air during the initial excision of the peritoneum and $2,400 \mathrm{cc}$ of blood was transfused during intra-abdominal exploration. A $14 \times 8 \mathrm{~cm}$ defect was detected in the posterior diaphragm (Figure 2).

The spleen was at the medial aspect of the abdomen and the hilum was actively bleeding. No splenectomy was performed. The stomach and the omentum in the left hemothorax were reduced back manually into the abdomen. The stomach was completely necrotic and the lesser curvature perforation was detected on the anterior aspect of the corpus (Figure 3).

A large hernia sac was detected in the diaphragmatic cavity. The defect in the posterior diaphragm was closed by primary repair following the insertion of a gastrostomy tube. After the improvement of hemodynamics and oxygen saturation of the patient, the dead fetus was delivered via

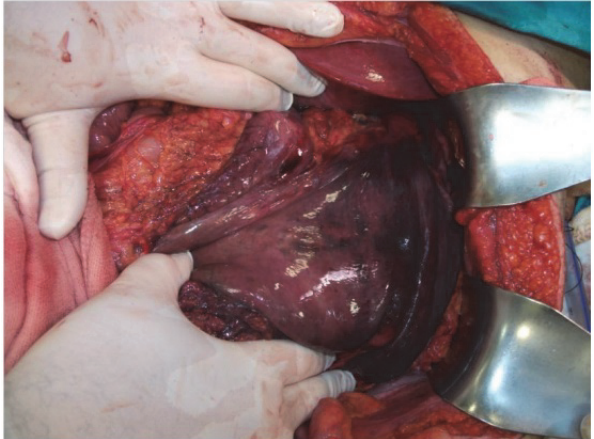

Figure 3: Total necrotic stomach.

caesarian section. Subsequently, total gastrectomy followed by Roux-en-Y anastomosis was performed. Postoperative follow-up of the patient was performed in the intensive care unit. On the 27th day of the treatment, the patient died due to brain hypoxia caused by cardiopulmonary arrest.

\section{Discussion}

Bochdalek hernia is the most common type of congenital diaphragm hernia (CDH) (90\%), followed by Morgagni hernia (1-5\%) and esophageal hernia (1-5\%) [2]. BH is mostly localized in the left posterolateral aspect of the diaphragm $(80-90 \%)$ and is twice more common in men than in women. Similarly, in our patient, the defect was located in the left side of the diaphragm. Bochdalek hernia often results from the herniation of abdominal organs into the thoracic cavity as a result of insufficient closure of the fusion between the posterolateral pleuroperitoneal membrane and the septum transversum [3]. Although $\mathrm{BH}$ is the most common type of $\mathrm{CDH}$, it is rarely seen in adults. However, some clinical conditions that elevate intra-abdominal pressure in adults, such as pregnancy, further increase the complication rate in $\mathrm{BH}[4]$.

Bochdalek hernia often presents with nonspecific symptoms. These symptoms may vary greatly, depending on the organs involved and the presence of strangulation. Although dyspnea and tachypnea are the most common presenting symptoms, patients with gastric volvulus often present with abdominal pain and vomiting. The case presented in this study had previously presented to the hospital several times with the complaints of dyspnea and abdominal pain but had no diagnosis. The literature shows that mortality has been reported in some of the patients with late diagnosis of $\mathrm{BH}$ [5]. Our patient presented to our emergency service with abdominal pain, nausea, vomiting, and dyspnea and had cardiopulmonary arrest during the initial examination. The patient was resuscitated by cardiopulmonary resuscitation but died on the 27th day of the treatment.

$\mathrm{X}$-ray is commonly used for establishing the diagnosis of $\mathrm{BH}$ but computed tomography is the gold standard in the diagnosis of BH. Computed tomography is highly useful in the visualization of the organs in the hernia sac in the diaphragmatic cavity as well as the clinical condition of the 
organs and the lungs. Our patient was immediately operated on under emergency conditions following the resuscitation due to the detection of free air in the left hemidiaphragm. In the literature, severe hemorrhage caused by the protrusion of the omentum in the thoracic cavity has been reported in patients with $\mathrm{CDH}$ [6]. However, similar to our patient, no hemorrhage caused by splenic laceration has been reported [7].

Laparoscopic repair and mesh repair, particularly in large defects, are the methods of choice in the treatment of $\mathrm{BH}$ [8]. In our patient, laparotomy was performed since the patient was unstable.

Bochdalek hernia is less common in adults compared to infants, and once the diagnosis has been established, $\mathrm{BH}$ should be operated on under elective conditions since it may lead to fatal complications in later stages.

\section{Competing Interests}

The authors declare that they have no competing interests.

\section{References}

[1] M. B. A. R. Islah and D. Jiffre, "A rare case of incarcerated bochdalek diaphragmatic hernia in a pregnant lady," Medical Journal of Malaysia, vol. 65, no. 1, pp. 75-76, 2010.

[2] Y. Chen, Q. Hou, Z. Zhang, J. Zhang, and M. Xi, "Diaphragmatic hernia during pregnancy: a case report with a review of the literature from the past 50 years," Journal of Obstetrics and Gynaecology Research, vol. 37, no. 7, pp. 709-714, 2011.

[3] W. S. Richardson and J. S. Bolton, "Laparoscopic repair of congenital diaphragmatic hernias," Journal of Laparoendoscopic \& Advanced Surgical Techniques, vol. 12, pp. 277-280, 2002.

[4] N. Barbetakis, A. Efstathiou, M. Vassiliadis, T. Xenikakis, and I. Fessatidis, "Bochdaleck's hernia complicating pregnancy: case report," World Journal of Gastroenterology, vol. 12, no. 15, pp. 2469-2471, 2006.

[5] S. Singh, A. Wakhlu, A. Pandey, S. N. Kureel, and J. D. Rawat, "Delayed presentation of strangulated congenital diaphragmatic hernia: learning from our experience," Hernia, vol. 17, no. 3, pp. 403-407, 2013.

[6] M. E. Coren, M. Rosenthal, and A. Bush, "Congenital diaphragmatic hernia misdiagnosed as tension pneumothorax," Pediatric Pulmonology, vol. 24, no. 2, pp. 119-121, 1997.

[7] T. Niwa, A. Nakamura, T. Kato et al., "An adult case of bochdalek hernia complicated with hemothorax," Respiration, vol. 70, no. 6, pp. 644-646, 2003.

[8] C. Palanivelu, M. Rangarajan, G. S. Maheshkumaar, and R. Parthasarathi, "Laparoscopic mesh repair of a Bochdalek diaphragmatic hernia with acute gastric volvulus in a pregnant patient," Singapore Medical Journal, vol. 49, no. 1, pp. e26-e28, 2008. 


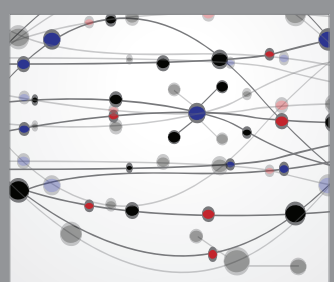

The Scientific World Journal
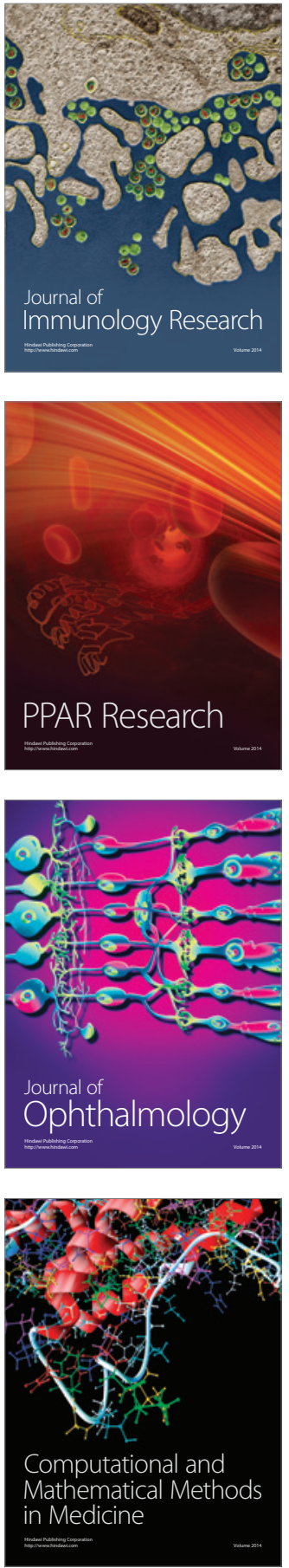

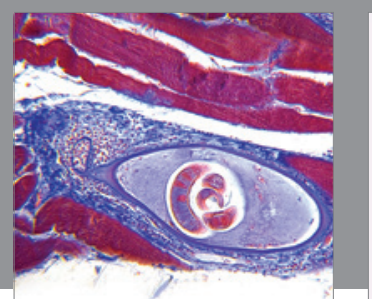

Gastroenterology Research and Practice

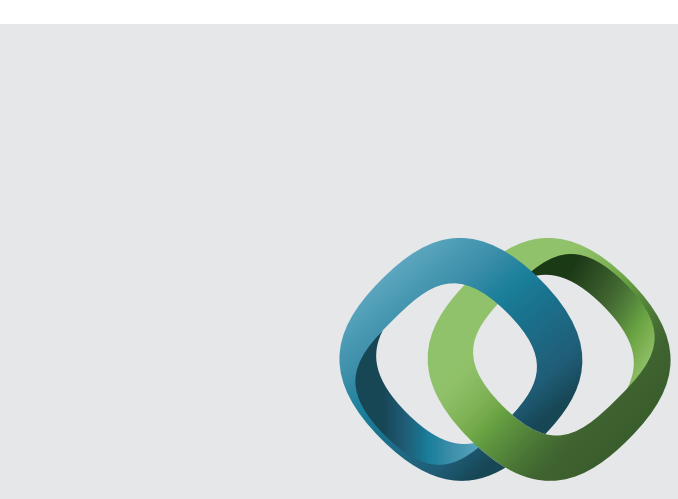

\section{Hindawi}

Submit your manuscripts at

http://www.hindawi.com
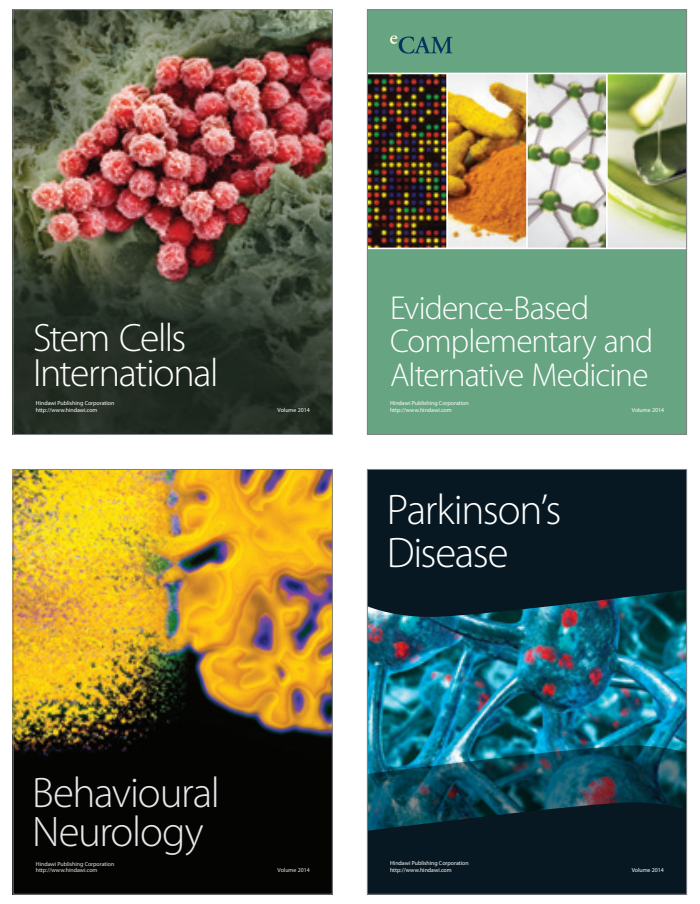
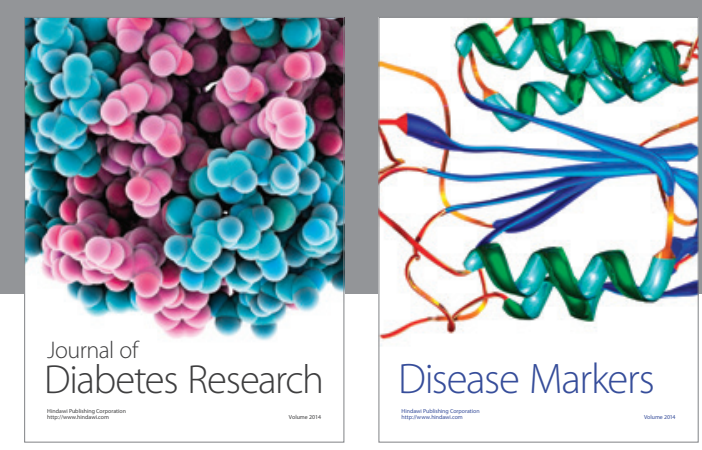

Disease Markers
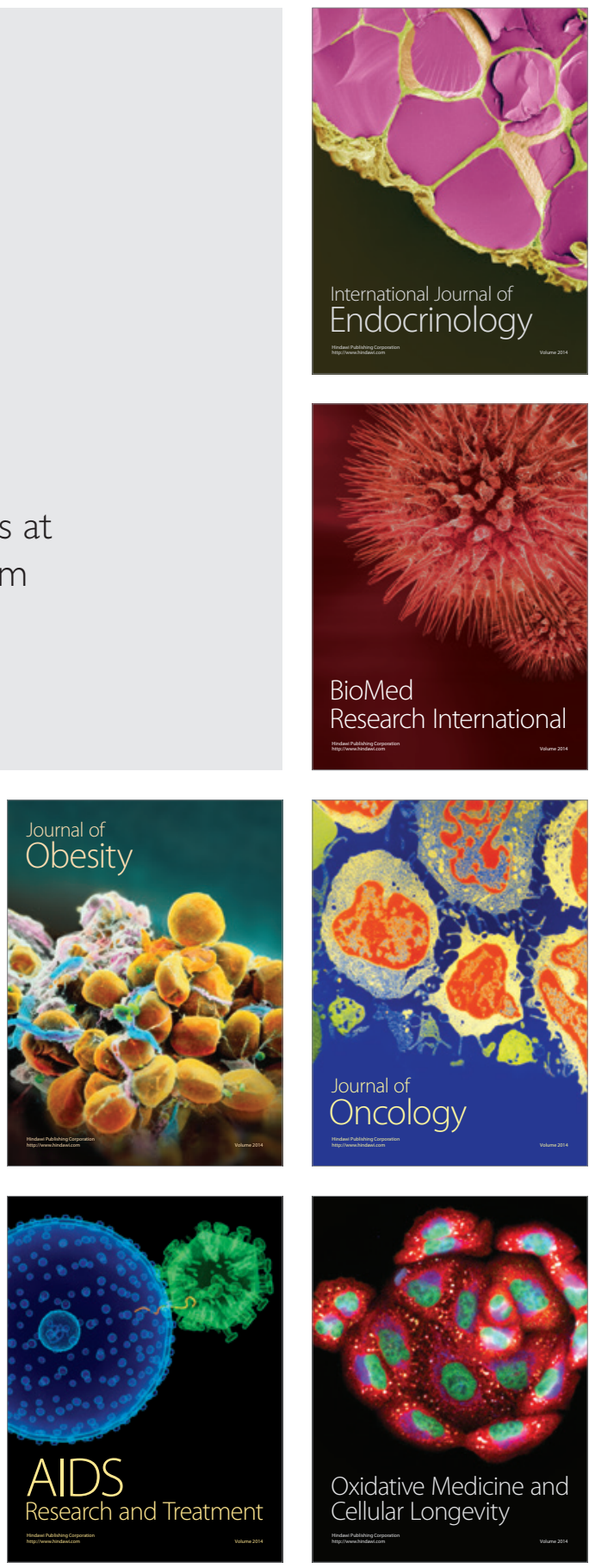